\title{
The development of a family resilience-strengthening programme for families in a South African rural community
}

\section{Serena Ann Isaacs (D) | Nicolette V. Roman | Shazly Savahl}

University of the Western Cape

\section{Correspondence}

sisaacs@uwc.ac.za

We thank the National Research Foundation of South Africa for its financial contribution in the completion of this project. We also thank all participants who made the time to be involved in the study.

\begin{abstract}
The aim of this study was to develop a contextually based family resilience program. Also presented here is a literature review of family resilience interventions suggesting that these 3 processes are the basis for effective family functioning. A close collaboration with the community ensured an adequate understanding of the presenting family challenges and this article describes the process in developing a program based on these challenges. A 3-round Delphi design was used for the study with international and local experts $(n=10)$ in the field of family and resilience studies and community stakeholders $(n=5)$. The program has three main aims: to increase family connectedness, family communication processes and social and economic resources. Based on the findings of this study, 4 modules will be presented to participants, "about family," "talking together," "close together," and "working together." A description is provided of the program content and decisions regarding logistical program concerns.
\end{abstract}

\section{1 | INTRODUCTION}

\subsection{Background and rationale}

The structures and systems within which families function continuously grow in its diversity (Seccombe, 2002) and families are increasingly in need of sufficient and adequate support. Changes within the wider social, economic, and political systems, such as rapid shifts in the economic climate and changing leadership and policies, can create difficulties for families and have lasting effects on the next generation (Hubler, Burr, Gardner, Larzelere, \& Busby, 2015). It is becoming progressively difficult for families to provide basic needs for its members, and according to Walsh (2016a), parents often provide for their families at great expense to themselves. One theoretic lens that is cognizant of both developmental and systemic factors concerning families and encourages the strengthening of family processes within adverse circumstances is Walsh's (2006, 2016a) theory of family resilience. 
Walsh (2006, 2016a) conceptualizes family resilience as a series of relational processes, which includes a family's communication processes, organizational patterns and their belief systems. Family resilience refers to the family's functioning within the context of adversity (Walsh, 2016a). A family resilience approach has three main goals: First, to reduce vulnerability in families; second, to enhance family functioning; and last, to mobilize family and community resources (Walsh, 2012). Family resilience theory argues that families can be empowered to not only beat but also challenge or even change their "odds" (Patterson, 2002; Secoombe, 2002; Walsh, 2016b) or circumstances by focusing on key family processes. This theory is also effective as an intervention frame. Its premise is that families are not unaffected by adverse events, but views families as being capable of meeting these challenges effectively while having an inherent ability to prosper (Walsh, 2012).

Having the ability to prosper, however, is not always easily achieved when the environment in which a family might find themselves experiences problems beyond the relational because of sociohistoric events and intrinsic and increasing structural inequalities. According to Maiorano and Mano (2017) South Africa remains one of the most unequal countries in the world, yet the "family" is often the targeted intervention site for policy developers in South Africa (Morison, Lynch \& McCleod, 2016) and is encouraged to be more resilient than the odds presented to them (Walsh, 2016). Many are underresourced, impoverished, and experience various psychosocial issues such as parental absences, single-income families, domestic and community violence, victimization owing to crime, substance abuse, teenage pregnancies, abuse in all its forms, unemployment, and depression (Adams et al., 2013). In other words, their adversities might exceed their ability to demonstrate their resilience. Far too many citizens live below the poverty line and struggle merely to survive. The structural injustices experienced by the many of the South African population cannot be improved by merely placing emphasis on theory and clinical practice.

The definition of the construct family is complex because of the varying meanings for each individual (von Backström, 2015). In the white paper for Families in South Africa (Department of Social Development, 2012), family is defined as a "societal group, related by blood (kinship), adoption, foster care or the ties of marriage (civil, customary or religious), civil union or cohabitation, and go beyond a particular residence." This definition has, however, been criticized for promoting a middle-class, heteronormative ideal by focusing on family structure and "stable, unified families" (Rabe, 2017), rather than the more important functioning (Morison et al., 2016). The emphasis on family structure, rather than functioning or processes, might demonstrate an ignorance intervention developers cannot afford. For example, each family has its own structure, functioning, and processes based on their belief systems or their family identity (Soliz, Thorson, \& Rittenour, 2009), which is beyond a simple definition. However, von Backström offers the following definition:

A group of individuals connected by kinship, marriage, adoption or affiliation. Members share an emotional bond with one another that stretches beyond the physical residence ... family would also engage in relationships with community and the broader society and these relationships are interrelated. $(2015, p .1)$

This definition, derived from Amoateng and Richter (2007), promotes the notion that families are connected beyond kinship, marriage, or civil union and focuses important family processes such the bond between those members and the interrelated societal systems.

The bond or cohesion between family members and the interconnection with the wider community are known as family connectedness (Walsh, 2012, 2016a). This is a critical process in increasing an individual's and family's positive development (Baer, 2002; Black \& Lobo, 2008) or connectedness (Walsh, 2006). Benzies and Mysachiuk (2009) also describe family cohesion as an essential factor in fostering family resilience. For example, Law, Cuskelly, and Carroll (2013) tested a model investigating the relationship between family connectedness and 563 children's psychosocial adjustment and found that the level of connectedness directly influenced children's psychosocial adjustment. This was similar to Stuart and Jose's (2014) study, which found positive correlations between family connectedness and ethnic identity and well-being of Maori adolescents. The quality of family relationships, regardless of family structure, more strongly predicted adjustment and well-being.

Manzi, Vignoles, Regalia, and Scabini (2006) theorized about the effect of enmeshment and cohesion on identity development, reported similar findings, and argued that identity development is moderated by culture, and 
therefore enmeshment might not necessarily be perceived as being negative or hindering in such development. In addition, Power et al. (2016) explored the complexities of family resilience processes and they also found that along with family connectedness being integral to family functioning, so was the connection and support found beyond the immediate family; in other words, their perceived social support and economic resources.

According to Walsh (2006), social connection and involvement in the community can function as a sense of security and belonging for the family. Benzies and Mysachiuk (2009) discuss the importance of interfamily processes and the connection between the family and the environment in a systematic review. Along with the presence of social support both within and outside of the home, they highlight the following factors that play an integral role in developing a family's resilience: access to quality childcare and schools, healthcare, a stable and adequate income, housing, and involvement in the community. Therefore, social and economic resources are an important part of family resilience (Walsh, 2016a). This is also consistent with research by Distelberg and Taylor (2015) and Power et al. (2016), who found that higher levels of family resilience were associated with greater use of external resources. Black and Lobo (2008) also describe social support to be a factor challenging to a family's resilience; however, it is increasingly undermined owing to the families' disconnect from society. Walsh (2016a) also theorizes that the current convention of "every family for themselves" makes it challenging for families to "reach out."

Along with social support and adequate economic resources, Jonker and Greeff (2009) found the style of communication among family members was the strongest predictor of family adaptation. The authors sought to identify the processes the families utilized while caring for a member with a mental illness. Communication (conveying and receiving messages between individuals both verbally and nonverbally) within families enhances problem-solving abilities during crises (Walsh, 2016a). The profound effect of family communication on family functioning has been established in several family-related studies (for example, Black \& Lobo, 2008; High \& Sharp, 2015; Ho et al., 2016; Prouty, Fischer, Purdom, Cobos, \& Helmeke, 2016; Schrodt \& Ledbetter, 2007).

Similarly, Liermann and Norton (2016) explored the relationship outcomes after participation in a 28-day Wilderness program. The aim of the program was to improve the relationship between parents and adolescents; specifically here, developing a common vocabulary with adolescent-parent dyads and listening was emphasized. After 6 months, communication was reported to be one of the most sustained outcomes. Parents also noted changes in the quality of their relationships. This is consistent with Walsh (2016a) and Offer (2013), who posit that family resilience processes have a synergistic effect. One process often speaks to, and is important to, the other. These processes described above also form part of Walsh's theory of family resilience (2006, 2016a).

If a family's level of resilience can increase family functioning within the context of adversity, does that absolve national leaders from the responsibility of ensuring adequate resources and systems for the betterment of well-being at an individual, family, and community level? Interestingly, some studies have found that there is also more to the success of a well-rounded family system than the mere addition of resources. Stiel, Estrella, Wang, and Distelberg's (2014) study found intangible resources such as adequate social support was an essential component of the success of resource-focused programs. The study evaluated 411 families who were enrolled within a resource-focused Family Self-Sufficiency Programme in California. Using discriminant functional analysis, the aim was to predict whether a family's employment status could be predicted by demographic and family resilience factors. They found that the presence of two factors in particular would more likely predict employment of the participants: social support, communication, and problem-solving skills (Stiel et al., 2014).

Similarly, the LINC model (whose aim is to increase individual, family, and community resilience) focuses not on increasing artificial services alone but also improving the use of existing resources (Landau, 2010). The LINC model of community resilience focuses on building and/or strengthening natural support systems-those who the family deal with on a daily basis (family clinics, neighbours, clergy, extended family) rather than focusing slowly on artificial support systems (therapists, social services, emergency personnel) in times of crisis (Landau \& Weaver, 2006). A family or community link, such as an individual or organization, who ensures the connection between outside assistance and the community, is established. In one example, LINC was used in Argentina to address the increase in youth in substance use. The treatment of substance use occurred within the traditional in-patient setting, resulting in the isolation of the patient for months at a time. Many parents were not in favor of this form of treatment. One of the outcomes 
of the assessment was requesting an outpatient community-based treatment and the "10000 Lideres para el Cambio" was developed. The collaboration with the community resulted in an increase in admissions as well as the likelihood of long-term recovery (Landau \& Weaver, 2006).

One intervention that draws on Walsh's (2003) family resilience theory and has, for more than a decade, shown to increase various family resilience processes is the Families OverComing Under Stress (FOCUS; Lester et al., 2013; Saltzman et al., 2011). Initially designed by the University of California, Los Angeles, and Harvard Medical schools for military families, FOCUS has expanded its target participants and is also implemented with civilian families (Saltzman, 2016). It has been found useful for families who experience different forms of stress such as loss, ill mental health, and trauma. FOCUS can also complement other forms of intervention. The eight-session, psychoeducative intervention begin with a meeting between the facilitator and the family, to clarify goals the family wishes to achieve. Parents and children are taught about important developmental milestones and tasks, family roles, and practical communication skills. According to Saltzman (2016), the intervention has shown strong outcomes for families who participate, as it is based on the comprehensive framework of Walsh.

Moreover, one of the only South African studies identified that focused specifically on one factor to increase family resilience is that of Holtzkamp (2010). She developed, implemented, and evaluated a family resilience enhancement program for two low-income communities in the Western Cape. The program was designed using Cafarella's (2002) 12 intervention guidelines. Holtzkamp (2010) focused on only one family resilience factor, that of family hardiness. Family hardiness encompassed family control, commitment, and challenges.

The manualized, once-off workshop was evaluated using mixed methods. Fifty (33 for the experimental group and 17 in the control group) participants were evaluated preintervention, postintervention, and once more 3 months after. Although no significant changes were detected, there was evidence of some increases found in some of the family functioning and attachment scales as well as differences reported by the families in the qualitative interviews. For example, some families reported an increase in the value they placed on family cohesion and open and honest communication. The small sample size and once-off intervention format could account for the findings.

The interventions described above (with the exception of Holtzkamp, 2010) are a few family resilience-based interventions identified by searching several databases available to us (such as Academic Search Complete, PsychArticles, SocIndex, Eric). The search terms were "family resilience intervention(s)," OR "family resilience programs" OR "Family resilience programs." Although this was by no means a systematic review, this could indicate a paucity of available family resilience-focused intervention research. Moreover, these studies demonstrate the potential of interventions using a strengths-based approach such as family resilience.

Strengthening family resilience processes through interventions have been shown to encourage transformation and growth (Acuña \& Kataoba, 2017; Stiel et al., 2014; Vermeulen \& Greeff, 2015). Multiple positive outcomes have been reported because of family-based research and interventions. Many existing programs are adopted from international developers and thus not developed from the same contextual circumstances and concerns as those from these studies setting as well as with the assistance of those under study (Holtzkamp, 2010). However, the development of an intervention should begin with a focus on the family's goals, current processes, their structure, and context (Walsh, 2016a). Therefore, the aim of the study is to describe the development of a program that enhances family resilience processes, in collaboration with those practising in the field of child, family, and resilience studies and the community stakeholders.

\section{2 | METHOD}

\section{1 | Research design}

The Delphi method was implemented in this study to generate ideas, based on participants' expertise, on the guidelines and content for the program. The Delphi was chosen because it is an iterative and useful process for program or model development (Skulmoski, Hartman, \& Krahn, 2007). Its flexibility is often critiqued because of the inability to replicate findings and other concerns in establishing rigour (Hasson \& Keeney, 2011). 
Different types of group-based methods exist that might also be applied in studies of this nature (such as group concept mapping, nominal groups, and focus groups). The challenge with these types of group-based approaches is often arranging for participants to meet at one place, at a time convenient for each participant. This was true even for this study. As noted below, given the participants' time schedules, the decision was made to proceed with the Delphi in a more convenient e-mail-based format. In the case of group concept mapping, even a web-based forum also presents challenges such as becoming familiar with a particular software. For example, Chang et al. (2017) describes an "easyto-use" concept mapping software in their study. However, using the Delphi via simple question and answer format participants were able to respond to set questions and, eventually, a questionnaire and not have to be too creative (i.e., first understanding new software and then responding to the questions).

However, there are also different types of Delphi conducted in research, formats that might be conceptually similar to focus, nominal groups, or even workshops. The most commonly implemented is the classic Delphi, which aims to elicit opinion and gain consensus amongst a panel of experts (Hasson \& Kenney, 2011). The format of this particular one was both web-based, in the form of e-mails, and in the form of a stakeholder focus group discussion. According to von der Gracht (2012), there is no golden standard in determining when participants reach the point of consensus and many researchers use a variety of methods including descriptive and inferential statistics and subjective criteria to make such a determination.

Data were collected in three rounds. The first round of the Delphi was qualitative and exploratory in nature, the findings of which were used to construct a questionnaire so that participants could rate their agreement of others' opinions (round 2; Hsu \& Sandford, 2007). The findings of the second round were then analyzed using descriptive statistics (frequencies and percentages). The findings of the first two rounds were presented to the community stakeholders, in the form of a focus group discussion, to elicit further discussion and decision making on the program. The community stakeholders are the final decision makers on the program structure and format. Although this cohort was involved only in the last round (not everyone had access to a computer and each trip to the community was a 4-hour journey), intervention development is not a linear process; therefore, if they were in disagreement or held different perspectives, it would be included in the findings. In addition, Hasson and Keeney (2011) note that a Delphi offers a cross-sectional view of expert opinion to inform and so must also be guided by other literature. Another form of guidance can also be informed by the input of the community stakeholder cohort.

\subsection{Preceding study phases and the research context}

The current study describes the processes undertaken to develop a family resilience program for families in a rural community along the West Coast of South Africa. This study forms part of a larger project with the same aim. The larger project uses a participatory action approach and the researchers closely collaborate with the local nongovernment organization (NGO). It was through this collaboration that the NGO identified the need to strengthen families within the community. The NGO served as a venue for the intervention and the staff were trained as facilitators of the program. This participatory action approach is central: (a) It ensures a continued relationship of trust between the researchers, NGO, and the community; (b) community members do not feel that it is merely more research through which nothing would emerge; and (c) the NGO would have evidence (provided through the research) to present to their funders. The family resilience assessment was converted to a report for the NGO on the reported family resilience needs of 656 families across the community. Once the intervention itself was implemented, we assisted the NGO in developing an evaluation and reporting plan.

The larger project was conducted in three phases ${ }^{1}$. Phase 1 aimed to identify and explore the family resilience needs using an explanatory sequential mixed methodological design. The quantitative component was conducted with assistance of fieldworkers and the collected data from 656 community members. Qualitative data were conducted in the form of four focus groups ( $n=27$ ). The needs of the community resulted in the identification of the potential outcomes for the program. These outcomes were defined as follows: increasing family connectedness, increasing the use of social

${ }^{1}$ The larger project is a PhD study conducted by SAI. 
and economic resources, and increasing family communication processes (Isaacs, Roman, \& Savahl, in press). Phase 2 was a systematic review aimed at identifying and describing practices and processes used in family-based intervention development. The findings indicated that most family-based interventions are strengths-based, psychoeducative in nature, makes participant engagement and retention a priority, and includes the involvement of the local community (Isaacs, Roman, Savahl, \& Sui, 2017).

The community in focus is a predominantly Afrikaans-speaking, rural community situated 4 hours outside of Cape Town, on the West Coast of South Africa. The first author (SAI) has an established relationship with the community's NGO because it is a site in which postgraduate psychology students complete their service-learning training. The crime and violence in this community are often a result of the unemployment and high substance use rates (Crime Stats, 2013). The local municipality reports that there are only two primary schools and no high school, so learners have to travel to the next town to gain a secondary education. This also contributes to low education levels because many learners prefer not to leave their homes.

Phase 3, which is the focus of this article, aimed to develop the community-based, family resilience program in collaboration with those practising in the field of child, family, and resilience studies and the community stakeholders. The aim of this article is to describe the processes involved in the development of the intervention.

\section{3 | Participants}

The participants of the Delphi included two cohorts. The first comprised international and national experts in the field of child, family, intervention development, and resilience and the second were local community stakeholders. The recruitment of the first cohort was initially conducted purposively. Participants were required to have knowledge of or experience in the field of family psychology, family resilience, and/or intervention development. The starting point for the search for potential participants was based on some of the authors identified in the systematic review in phase 2 of the larger project. Forty-two participants were initially contacted, via e-mail, with a request to participate in a two-round Delphi. The response rate was expectedly slow and the participants were asked to nominate other possible participants. The recommended individuals were also contacted.

Although 12 participants confirmed their interest and provided consent to be part of the panel, two participants dropped out. Ten participants (age, mean $[M]=48.75$; standard deviation $[S D]=10.98$ ) were in the final sample. The participants resided in different countries: Australia $(n=1)$, the United States $(n=2)$, Canada $(n=1)$, Portugal $(n=1)$, and South Africa $(n=7)$. Table 1 provides the demographic information and field of expertise per participant:

For the third round of the Delphi, five staff members (age, $M=38.80 ; S D=12.52$ ) of the NGO (qualified social workers and the director of an organization) participated in the focus group discussion. Rowe and Wright (2011) agree that experts and lay people together increase the variety of perceptions and can add depth to the information. They were able to provide input on the findings and recommendations as well as the feasibility of the program because of their knowledge and experience. Table 2 describes the demographic information of the sample for round 3.

\section{4 | Procedures}

The procedures followed are outlined in the Figure 1 and described in terms of each round of the Delphi.

\subsubsection{Round 1}

As is typically the case, the first round of data collection was primarily aimed at idea generation (Hsu \& Sandford, 2007; Skulmoski et al., 2007) and was exploratory in nature. The participants received an information pack containing a brief overview of the aim and the findings of the larger project (Appendix 1). The participants were given this information to assist in their reflection of the process and guide their reasoning when responding over the course of the Delphi. They were presented with four questions, two of which were defined by van Oostrom et al. (2007) for intervention development. 
TAB LE 1 Expert panel participants details

\begin{tabular}{|c|c|c|c|c|}
\hline Gender & Age & Title & Country & Speciality \\
\hline Male & $\mathrm{n} / \mathrm{a}$ & Professor & South Africa & Family research \\
\hline Male & 63 & Professor & South Africa & Family resilience expert \\
\hline Female & 56 & Professor & South Africa & Applied and community psychology \\
\hline Male & 44 & $\mathrm{Mr}$ & South Africa & $\begin{array}{l}\text { Community, trauma, substance use psychology, } \\
\text { especially in low-income areas/experience in the } \\
\text { community }\end{array}$ \\
\hline Female & 31 & Mrs & South Africa & $\begin{array}{l}\text { Clinical psychologist. Specializes in child psychology } \\
\text { and attachment-based therapy. }\end{array}$ \\
\hline Female & 56 & Professor & South Africa & Applied and community psychology \\
\hline Female & 45 & Professor & South Africa & $\begin{array}{l}\text { Family studies, especially in terms of family role } \\
\text { identity }\end{array}$ \\
\hline Female & $\mathrm{n} / \mathrm{a}$ & Doctor & Australia & $\begin{array}{l}\text { Research in treatment of childhood, behavioral } \\
\text { problem, specializes in cultural tailoring of programs }\end{array}$ \\
\hline Female & $\mathrm{n} / \mathrm{a}$ & Doctor & Canada & Resilience studies \\
\hline Female & 38 & Doctor & Portugal & Family intervention development \\
\hline Female & 57 & Professor & USA & Family research and intervention development \\
\hline Female & $\mathrm{n} / \mathrm{a}$ & Doctor & USA & Family studies, applied and community psychology \\
\hline
\end{tabular}

TAB LE 2 Community stakeholder participant details

\begin{tabular}{lll} 
Gender & Age & Affiliation \\
\hline Male & 45 & NGO \\
Male & 32 & NGO \\
\hline Female & 29 & NGO \\
\hline Female & 30 & NGO \\
\hline Female & 58 & NGO \\
\hline
\end{tabular}

\begin{tabular}{|c|c|c|c|c|}
\hline Round 1 & & Round 2 & & Round 3 \\
\hline $\begin{array}{l}\text { Exploratory } \\
\text { Four } \\
\text { questions } \\
n=10 \\
\text { Content } \\
\text { analysis }\end{array}$ & $\stackrel{\text { weeks }}{\longrightarrow}$ &  & $\stackrel{\text { weeks }}{\longrightarrow}$ & $\begin{array}{c}\text { Workshop } \\
\text { Round-table } \\
\text { discussion } \\
n=5 \\
\text { Content } \\
\text { analysis }\end{array}$ \\
\hline
\end{tabular}

FIGURE 1 Outline in the Delphi process

- Reflect on the process presented thus far. What would you agree or disagree with as the main performance outcomes of the family resilience program?

- What does the target population (families) need to learn or acquire with regard to the specific outcome to achieve the performance objective?

- What needs to be changed for the target population to achieve the performance objective (program outcomes/change objectives)?

- Do you have any other thoughts/comments/suggestions? 
The responses were collated after three weeks (Okoli \& Pawlowski, 2004) of the first round of the Delphi (see the Results section). One participant decided to withdraw from the process, during the first round, because she was not sure whether she would be able to provide valuable input.

A six-round thematic analysis (Braun \& Clarke, 2006) was used on the collated responses and generated two thematic categories with a total of six themes. Hsu and Sandford (2007) suggest that the responses be analyzed and converted into a structured questionnaire, which are then used for the second round. The themes and codes were formulated into items and a 103-item questionnaire (see Appendix 2).

\subsection{2 $\quad$ Round 2}

Participants were allocated a time of 2 weeks within which to complete the questionnaire. The participants were asked to rank their opinions of the items on a Likert scale (strongly agree to strongly disagree). However, they were not asked to rank their opinion of the importance of an item.

During round 2, one more participant had shown interest in being part of the study. Because attrition was already a concern, she was included in round 2 , and she received the information regarding round 1 . Unfortunately, after several e-mails, one participant was no longer contactable and the number of participants remained at 10 . Ten responses were captured on Excel and then analyzed for frequencies and percentages using SPSS version 24.

For Hsu and Sandford (2007), studies reporting both percentage and measures of central tendency (such as the mean, median and mode) are useful in analyzing participants' responses. This aids in reducing subjectivity between Delphi rounds (Holey, Feeley, Dixon, \& Whittaker, 2007). Because only 10 participants responded, it was important to note the patterns and percentage of responses on the items. No rating of response was required. According to McMillan, King, and Tully (2016), conducting more than two rounds can increase attrition; therefore, we decided to end the involvement of the expert cohort and began collating the already-generous amount of data for round 3.

\subsection{3 | Round 3}

The findings were presented to the community stakeholders as the third round of the Delphi. They were not included in the previous Delphi rounds specifically because they have been involved in most of the larger project already. Thus, we could gain a sense of outsider or "expert" perspectives on the larger and current study (in rounds 1 and 2) before integrating the opinions of the stakeholders.

Round 3 was completed in a 2-hour roundtable discussion. This round focused on (a) providing feedback to the stakeholders on previous rounds, (b) presenting the suggested program guidelines, and (c) discussing additional considerations presented by stakeholders. During this discussion, a cofacilitator assisted SAI (researcher) in keeping detailed notes on the workshop, to ensure an accurate reflection of the roundtable discussions. The discussion was also audiotaped and transcribed verbatim. Braun and Clarkes' (2006) thematic analysis was conducted on the transcript as well as on the notes taken during the discussions.

\section{5 | Ethics}

The university's ethics review board provided ethics approval for the larger project. Informed consent was obtained from all participants involved and were all signed and returned. Confidentiality was assured because each participant e-mailed the researcher personally and therefore had no knowledge of another individual's response. Confidentiality was also assured to those who participated in the roundtable discussions. This was ensured to the extent that the researcher would not allow others who were not involved in the research to be able to identify individual participants or their responses. To this end, they signed two forms: a consent form and a focus group confidentiality form. Participants were also free to withdraw from the process at any time. Two participants, during the first and second round of the Delphi, practiced this autonomy. The participants were recused without prejudice. 
TABLE 3 Thematic categories and themes

\begin{tabular}{|ll}
\hline Thematic category & Theme \\
\hline 1. Programme outcome considerations & 1.1 Family connectedness \\
& 1.2 Utilizing social and economic resources \\
& 1.3 Family communication \\
\hline 2. Intervention format and logistics & 1.4 About family
\end{tabular}

\section{3 | RESULTS}

\section{1 | Round 1}

As recommended by Hsu and Sandford (2007), each round is analyzed and reported on separately. Participants provided their understanding and opinions of the proposed program outcomes of the family resilience program in answer to the four questions presented. Two thematic categories, one category with four themes and another with two themes, were identified during the analysis. This is presented in Table 3 below.

\subsection{1 | Program outcome considerations}

The first three themes found in round 1 centered on the three proposed outcomes: increasing family connectedness, utilizing social and economic resources, and family communication. The expert panel also provided suggestions of "change" elements that would need to be in place for the program outcomes to be realized. This theme was labelled about family. It is centered on family members' ability to reflect on their family life and make a commitment to see positive change. Furthermore, one of the main aims of this theme is creating a sense of family identity.

\subsection{2 | Intervention format and logistics}

The participants also provided suggestions for the format of the intervention and other factors that could increase the success of the program. Participants felt that the program should include learning (psychoeducation principles), be action-based, and should focus on developing skills. In addition, some recommended that decisions on program logistics should be made in collaboration with the community.

As previously described, the codes were turned into items and arranged by its appropriate theme for the questionnaire.

\subsection{Round 2}

All participants received the questionnaire and were instructed to select the option that best suited their opinion on each item. All items were presented with their frequencies and percentages. Some participants did not answer each item. In some cases, it is clear that it was an oversight (when a participant had answered every other item) and in others, participants provided comment, which explained their abstention. This is included in the Discussion section.

In each table below, the theme was provided with a statement of opinion, such as "family connectedness should include ... mutual appreciation of family members." Participants responded on a Likert scale. Their frequencies are presented along with the percentage of agreement with the statement.

Table 4 focuses on the theme of family connectedness (FC) and its dimensions as was shared by the panel experts. They were then required to rate their opinions of the items. Some participants shared dissenting opinions on two of the items. These items were "FC should include (item 16) interconnectedness with the larger community" and "FC should include (item 14) an understanding of one's own emotions." Fifty percent of the participants felt that FC should remain focused on the family alone and should not include the interconnectedness with the larger community. Further, in response to item 14, in the comment section, one participant reported concern regarding the level of difficulty 
TAB LE 4 Feedback on proposed program outcome: Family connectedness

\begin{tabular}{|c|c|c|c|c|c|}
\hline & $\begin{array}{l}\text { Strongly } \\
\text { Agree }\end{array}$ & Agree & Disagree & $\begin{array}{l}\text { Strongly } \\
\text { Disagree }\end{array}$ & $\begin{array}{l}\% \text { in } \\
\text { agreement }\end{array}$ \\
\hline \multicolumn{6}{|l|}{ Family connectedness should include/refers to... } \\
\hline 1....mutual appreciation of family members & 7 & 3 & & & 100 \\
\hline 2.... positive emotions & 5 & 3 & 2 & & 80 \\
\hline 3....mutual knowledge of each other & 7 & 3 & & & 100 \\
\hline 4. ....altruism & 2 & 6 & 1 & & 80 \\
\hline 5....family time moments & 6 & 4 & & & 100 \\
\hline 6....kindness & 4 & 5 & 1 & & 90 \\
\hline 7....empathy & 6 & 4 & & & 100 \\
\hline 8. ...positive humour & 2 & 6 & 2 & & 80 \\
\hline 9....positive attention & 5 & 4 & 1 & & 90 \\
\hline 10....sensitivity to each other's' needs & 9 & 1 & & & 100 \\
\hline 11....certain family rituals/routines/ activities & 8 & 1 & 1 & & 90 \\
\hline $\begin{array}{l}\text { 12. ...family members acknowledging their responsibilities } \\
\text { within the family }\end{array}$ & 4 & 3 & 3 & & 70 \\
\hline 13....the understanding of members' roles & 4 & 3 & 2 & 1 & 70 \\
\hline 14....understanding of own emotions & 3 & 2 & 3 & 2 & 50 \\
\hline $\begin{array}{l}\text { 15. ... recognition of individualisation \& struggling together } \\
\text { for a common purpose }\end{array}$ & 5 & 4 & & 1 & 90 \\
\hline 16....include interconnectedness with the larger community & 2 & 3 & 5 & & 50 \\
\hline 17....emotional responsiveness of family members & 7 & 3 & & & 10 \\
\hline $\begin{array}{l}\text { 18. ...the capacity of family members to recognize and } \\
\text { respond appropriately to socioemotional needs }\end{array}$ & 4 & 6 & & & 10 \\
\hline $\begin{array}{l}\text { 19....spending quality time together without a required } \\
\text { outcome }\end{array}$ & 6 & 3 & & & 90 \\
\hline 20....family members being explicit of own needs & 5 & 2 & 3 & & 70 \\
\hline 21. Is not about rules and boundaries within the family & 3 & 2 & 3 & 1 & 50 \\
\hline $\begin{array}{l}\text { 22. Has the potential for making each member of the family } \\
\text { feel supported }\end{array}$ & 7 & 2 & & & 90 \\
\hline $\begin{array}{l}\text { 23. Has a structured dimension which refers to daily living } \\
\text { and functioning }\end{array}$ & 3 & 4 & 2 & & 70 \\
\hline $\begin{array}{l}\text { 24. Has an unstructured dimension, which refers to } \\
\text { engagement of family members (such as clarifying who } \\
\text { does what?) }\end{array}$ & 4 & 4 & 1 & & 80 \\
\hline
\end{tabular}

the family might experience in an intervention if the concept of "understanding one's own emotions" should emerge. This concern was taken to round 3 so that the community stakeholders could decide whether it should be an included guideline.

From Table 4 it is evident there was general agreement that there be a focus on the structured and unstructured component of FC. The participants agreed (70\%) that the structured component includes daily living and functioning, routines and rituals, and an understanding of the roles that each family member plays. They also agreed (80\%) that the unstructured dimension would include enhancing the level of engagement between family members. In addition, the level of engagement would also include fostering positive emotions (good humour, attention, kindness, altruism) toward one another and an appreciation for the roles and rituals and daily functioning.

The participants mostly agreed with for Utilising Social and Economic Resources, there is a subjective (90\%) and structured/objective (100\%) dimension of utilizing both social and economic resources. The structured or objective 
TAB LE 5 Feedback on proposed outcome: Utilizing social and economic resources

\begin{tabular}{|c|c|c|c|c|c|}
\hline Utilizing socioeconomic resources & $\begin{array}{l}\text { Strongly } \\
\text { agree }\end{array}$ & Agree & Disagree & $\begin{array}{l}\text { Strongly } \\
\text { disagree }\end{array}$ & $\begin{array}{l}\% \\
\text { agreement }\end{array}$ \\
\hline \multicolumn{6}{|l|}{ Should include... } \\
\hline 25....an exploration of the resources available & 10 & & & & 100 \\
\hline 26. ....an intervention should include stress management & 1 & 4 & 5 & & 50 \\
\hline 27. ...learning about resources and rights to resources & 10 & & & & 100 \\
\hline 28. ...the barriers to accessing and utilizing the resources & 10 & & & & 100 \\
\hline $\begin{array}{l}\text { 29. ...the broader community and local government } \\
\text { engagement }\end{array}$ & 6 & 3 & 1 & & 90 \\
\hline $\begin{array}{l}\text { 30. ... has a subjective dimension such as how they make } \\
\text { sense of finances }\end{array}$ & 6 & 3 & 1 & & 90 \\
\hline $\begin{array}{l}\text { 31....has an objective dimension such as the actual income } \\
\text { and expenditure of the family }\end{array}$ & 7 & 3 & & & 100 \\
\hline $\begin{array}{l}\text { 32. ... increasing the use of social and economic resource } \\
\text { facilities }\end{array}$ & 8 & 2 & & & 100 \\
\hline $\begin{array}{l}\text { 33. ...providing pamphlets, service details, contact } \\
\text { information of available resources }\end{array}$ & 6 & 3 & & & 90 \\
\hline 34. Budgeting & 6 & 4 & & & 100 \\
\hline 35....how to talk about financial matters & 5 & 2 & 2 & & 70 \\
\hline 36. ...how to prioritize family financial needs & 6 & 3 & & 1 & 90 \\
\hline 37. It will be important to make "reaching out" easy & 6 & 2 & & 1 & 80 \\
\hline 38. Is important in resource-constrained settings & 7 & 2 & & & 90 \\
\hline
\end{tabular}

dimension would involve an exploration and learning of available resources, learning how to budget and creating useful information briefs. The subjective dimension should involve how the family thinks about and makes meaning of social resources and economic resources such as the local NGO, extended families, and friends. In addition, participants felt that "reaching out" should be made easier (80\%) for the participants of the program. In other words, in accordance with the LINC model, program facilitators and the NGO should play a more active role in establishing the links between families and social and economic resources.

It is clear from Table 6 that participants agreed and are in favor of most of the dimensions they believed form part of increasing effective family communication. Such a program component would aim to develop positive communication skills in terms of verbal and nonverbal communication, listening, and learning to talk to one another (100\%). It would also be important to develop effective communication regarding conflict resolution and talking about problems (100\%). Additionally, most of the participants also agreed that communication was important for family connectedness and consistent with research by Offer (2013) and Walsh (2003).

The theme of about family centers on elements necessary for change within potential program participants. Participants felt that it would be beneficial for families to first reflect on their family and their strengths and make a commitment to their family. Generally, participants put forth that what needs to change would be previous behaviors and cognitive processes about family and past experiences. This could be encouraged by reflecting on family history (80\%) and strengths and weaknesses (100\%) and making a commitment to one another (90\%).

Tables 8 and 9 describe additional format and logistical considerations that participants' provided in terms of intervention development.

Participants believed that the intervention should be not only focused on psychoeducation but also action-based. Therefore, family members should practice the skills learned during the intervention at home (100\%). The participants mentioned that although facilitators could be local community members, there are some aspects of the intervention 
TAB LE 6 Feedback on proposed outcome: Family communication processes

\begin{tabular}{|c|c|c|c|c|c|}
\hline Family communication processes & $\begin{array}{l}\text { Strongly } \\
\text { agree }\end{array}$ & Agree & Disagree & $\begin{array}{l}\text { Strongly } \\
\text { disagree }\end{array}$ & $\begin{array}{l}\% \text { in } \\
\text { agreement }\end{array}$ \\
\hline \multicolumn{6}{|l|}{ Should include/refers to... } \\
\hline 39....developing positive communication skills & 10 & & & & 100 \\
\hline 40. ...emotions in family & 8 & 1 & 1 & & 90 \\
\hline 41....family times for planning activities & 5 & 5 & & & 100 \\
\hline 42....Family members' decision-making & 5 & 5 & & & 100 \\
\hline 43....sharing personal experiences & 8 & 1 & 1 & & 90 \\
\hline 44. ...the act of talking together & 8 & 2 & & & 100 \\
\hline 45....generational communication & 7 & 2 & & & 90 \\
\hline 46.....an increase awareness of non-verbal communication & 7 & 3 & & & 100 \\
\hline 47....an increase awareness of how messages are sent & 8 & 1 & 1 & & 90 \\
\hline 48....problem solving & 7 & 3 & & & 100 \\
\hline 49....conflict resolution & 8 & 2 & & & 100 \\
\hline 50 ....increasing connectedness within family & 5 & 4 & & & 90 \\
\hline $51 . .$. verbal and nonverbal communication & 8 & 2 & & & 100 \\
\hline $\begin{array}{l}\text { 52. ...the practice of talking together-tone, gestures, } \\
\text { physical presence, body language }\end{array}$ & 8 & 2 & & & 100 \\
\hline $\begin{array}{l}\text { 53. ...how family members react-learn to talk about } \\
\text { problems }\end{array}$ & 9 & 1 & & & 100 \\
\hline 54....listening & 9 & 1 & & & 100 \\
\hline $55 . .$. is the bedrock of everything and all relationships & 4 & 3 & 2 & & 70 \\
\hline 56....building new ways of communication & 6 & 4 & & & 100 \\
\hline 57....conversations about relationships & 3 & 6 & & & 90 \\
\hline $\begin{array}{l}\text { 58. ...basic empathic responding skills-to verbalize what } \\
\text { they see }\end{array}$ & 8 & 2 & & & 100 \\
\hline $59 . .$. develop a vocabulary of feeling words & 7 & 3 & & & 100 \\
\hline $\begin{array}{l}\text { 60. Communication processes are important for increasing } \\
\text { connectedness with inside and outside resources }\end{array}$ & 5 & 4 & & & 90 \\
\hline
\end{tabular}

(80\%) that should be facilitated by individuals with more expertise. Fortunately, the NGO staff include qualified social workers who are members in the community.

Table 9 merely describes additional comments of the Delphi process that were expressed by participants in the previous round. One participant felt that the intervention developers should consider buying and adapting existing family programs; however, $50 \%$ of the participants disagreed with this. Moreover, this study endeavored to develop guidelines for a contextually based program using a participatory action research approach, and therefore community members would be involved in its development, implementation, and evaluation. Purchasing program material, which might not be contextually relevant, would not have been feasible.

\subsection{Round 3}

The roundtable discussion commenced with a review of the entire research process as well as the results from rounds 1 and 2. The aim of this round was to reach consensus amongst the staff of the NGO in terms of the program outcomes and guidelines put forth by the previous cohort and brainstorm ideas around new ideas or input. One main thematic category with two subthemes emerged: 
TABLE 7 About family

\begin{tabular}{|c|c|c|c|c|c|}
\hline About family & $\begin{array}{l}\text { Strongly } \\
\text { agree }\end{array}$ & Agree & Disagree & $\begin{array}{l}\text { Strongly } \\
\text { disagree }\end{array}$ & $\begin{array}{l}\% \text { in } \\
\text { agreement }\end{array}$ \\
\hline \multicolumn{6}{|l|}{ Families would need to... } \\
\hline 61. ... invest in their family & 7 & 2 & & & 90 \\
\hline 62. ...dedicate or devote specific time for their families & 7 & 3 & & & 100 \\
\hline 63. ... reflect on and recognize family strengths & 10 & & & & 100 \\
\hline 64....reflect on both past successes and failures & 6 & 3 & 1 & & 90 \\
\hline 65....committed to one another & 7 & 2 & 1 & & 90 \\
\hline 66. ....reflect on how they see family and their own family & 8 & 2 & & & 100 \\
\hline 67. ....recognize the importance of family & 9 & & 1 & & 90 \\
\hline 68. ... reflect on the benefits of being part of a family & 9 & & 1 & & 90 \\
\hline 69. Reflect on family history & 5 & 3 & 2 & & 80 \\
\hline 70.... reflect on strengths and weaknesses of the family & 7 & 3 & & & 100 \\
\hline $\begin{array}{l}\text { 71. ... reflect on parenting styles and skills practiced in the } \\
\text { home }\end{array}$ & 6 & 4 & & & 100 \\
\hline 72. ... respect one another & 8 & 1 & 1 & & 90 \\
\hline 73. ... reflect on family centeredness vs individuality & 5 & 3 & 2 & & 80 \\
\hline $\begin{array}{l}\text { 74. ... be encouraged to reach out and seek assistance when } \\
\text { needed }\end{array}$ & 6 & 3 & 1 & & 90 \\
\hline 75....unpack or reflect on socialisation processes & 4 & 3 & 3 & & 70 \\
\hline 76. ... be open to new ways of doing things & 6 & 4 & & & 100 \\
\hline 77....bring about the change within the family & 8 & 1 & 1 & & 90 \\
\hline 78....shift their own perspectives & 5 & 2 & 2 & & 70 \\
\hline 79. ... have critical discussions about family & 4 & 3 & 3 & & 70 \\
\hline $\begin{array}{l}80 . \text {... reflect on unhealthy styles-get rid of old patterns and } \\
\text { ways of relating }\end{array}$ & 5 & 4 & 1 & & 90 \\
\hline
\end{tabular}

\subsubsection{The Family Resilience Strengthening Programme (FRSP)}

First, this cohort felt that each proposed outcome was given due consideration and was in agreement with the content and guidelines. They felt that about family should be included as a component of the program because it would be important to first have families reflect and make a commitment to process of the FRSP. They believed that each program outcome should be an offered module. The decision was that there should be four modules: about family, talking together, working together, and closer together. In this way, there would be sufficient focus on each outcome and intervention targets would participate in each module for a period to increase retention of the knowledge and skills they would learn.

\subsection{2 | FRSP structure and format}

Second, most of their feedback focused on the format of the program. The stakeholders also expressed that home visits were possible and a good method for program implementation. They felt it would also help with both having program participants invest in their families and the program and an increase in retention rates. The participants also suggested a manualized program and that there should be different versions of the manual, for example, one for the program facilitators and one for the participants. It was also decided that before it can be officially implemented, it should be piloted before it is formally implemented. Based on the discussion and decisions made, the FRSP is outlined in the Table 11 below. 
TAB LE 8 Intervention format and implementation considerations

\begin{tabular}{|c|c|c|c|c|c|}
\hline Intervention format and implementation considerations & $\begin{array}{l}\text { Strongly } \\
\text { agree }\end{array}$ & Agree & Disagree & $\begin{array}{l}\text { Strongly } \\
\text { disagree }\end{array}$ & $\begin{array}{l}\% \text { in } \\
\text { agreement }\end{array}$ \\
\hline 81. Families members should map existing strengths & 8 & 1 & & & 90 \\
\hline $\begin{array}{l}\text { 82. "Learning" might not be an appropriate format for this } \\
\text { intervention }\end{array}$ & 3 & 4 & 2 & 1 & 70 \\
\hline 83. The intervention should be experientially based & 8 & 2 & & & 100 \\
\hline $\begin{array}{l}\text { 84. An aspect of the intervention should be education-based } \\
\text { if past experiences of families were not conducive to } \\
\text { learning resilience processes }\end{array}$ & 1 & 8 & 1 & & 90 \\
\hline $\begin{array}{l}\text { 85. The intervention should incorporate an integrative, } \\
\text { case-based tailored program }\end{array}$ & 6 & 2 & 2 & & 80 \\
\hline $\begin{array}{l}\text { 86. Skills should be taught, implemented, discussed and } \\
\text { refined }\end{array}$ & 7 & 2 & 1 & & 90 \\
\hline $\begin{array}{l}\text { 87. Adult-learning principles (not a lecture) should be } \\
\text { incorporated into the intervention }\end{array}$ & 7 & 3 & & & 100 \\
\hline $\begin{array}{l}\text { 88. The intervention should mirror what you want to have } \\
\text { happen in the process }\end{array}$ & 6 & 3 & & & 90 \\
\hline $\begin{array}{l}\text { 89. The intervention should be action-based; it should include } \\
\text { activity }\end{array}$ & 7 & 3 & & & 100 \\
\hline $\begin{array}{l}\text { 90. A preferred consideration should be to use local } \\
\text { community facilitators (as opposed to unfamiliar "expert" }\end{array}$ & 4 & 4 & 2 & & 80 \\
\hline $\begin{array}{l}\text { 91. Affordability and accessibility are important for } \\
\text { intervention development }\end{array}$ & 9 & & 1 & & 90 \\
\hline $\begin{array}{l}\text { 92. The choice of facilitators, its duration, venue or settings } \\
\text { and evaluation of the intervention should be considered } \\
\text { in conjunction with community stakeholders }\end{array}$ & 6 & 3 & 1 & & 90 \\
\hline
\end{tabular}

\section{4 | DISCUSSION}

The findings of this study (and the previous study's phases) contributed to the development of the FRSP, a strengthsbased, psychoeducative intervention that is aimed at increasing the family resilience processes of multichallenged families. The module outcomes of the FRSP are well aligned with Walsh's theory on family resilience. For example, the importance of adequate socioeconomic resources and family connectedness are directly related to the theoretical dimension of family organisational patterns (Walsh, 2016a). Family communication is also a dimension of the family resilience theory (Walsh, 2006, 2016a) and also arises as essential in family functioning in the literature (Jonker \& Greeff, 2009; Liermann \& Norton, 2016; Schrodt \& Ledbetter, 2007).

Participants of the study believed that families should reflect on and make a commitment to change within their families, or at least be open to possible shifts in their current functioning. In other words, consideration should be given to the current functioning, processes, and goals that they might have for their own family. If the families themselves have not yet considered this, then program facilitators should help families in their reflections and formulations of goals (Walsh, 2016b). The community stakeholder cohort felt that such a module should be offered first. It was named About Family. This is also consistent with studies such as Riley et al. (2008), whose first meeting with the parent and youth group is aimed at establishing a sense of group identity and a list of family goals. This concept can be extended further in this particular module to the notion of family identity. Family identity is the extent to which family members identify as being similar to or part of the family unit (Soliz et al., 2009). Although variations within individual and family identity is inevitable, it is important that participants feel that they do belong to the family unit. About family will also be an important initial step in the process the family will be undertaking as part of the program. Walsh (2016b) also argues that ensuring that the family is "on the same page" in terms of intervention goals and realistic family capabilities is crucial to the effectiveness of the intervention. 
TABLE 9 Other considerations/thoughts/comments

\begin{tabular}{|c|c|c|c|c|c|}
\hline Other considerations & $\begin{array}{l}\text { Strongly } \\
\text { agree }\end{array}$ & Agree & Disagree & $\begin{array}{l}\text { Strongly } \\
\text { disagree }\end{array}$ & $\begin{array}{l}\% \text { in } \\
\text { agreement }\end{array}$ \\
\hline $\begin{array}{l}\text { 93. The intervention should draw from the strengths found } \\
\text { (i.e., belief systems) in the needs assessment to develop } \\
\text { the lower qualities }\end{array}$ & 7 & 3 & & & 100 \\
\hline $\begin{array}{l}\text { 94. There is a synergistic effect between the proposed } \\
\text { intervention outcomes }\end{array}$ & 5 & 4 & & & 90 \\
\hline 95. The intervention will help family members feel valued & 4 & 5 & & & 90 \\
\hline $\begin{array}{l}\text { 96. Working in a rural community provides unique benefits in } \\
\text { terms of access }\end{array}$ & 4 & 2 & 2 & & 60 \\
\hline $\begin{array}{l}\text { 97. The inclusion of educational and career development } \\
\text { skills will be beneficial for the intervention }\end{array}$ & 2 & 6 & 2 & & 80 \\
\hline $\begin{array}{l}\text { 98. The intervention would need to be culturally and } \\
\text { contextually appropriate }\end{array}$ & 8 & 2 & & & 100 \\
\hline $\begin{array}{l}\text { 99. The intervention developers should consider buying and } \\
\text { adapting curricula for the development of the Family } \\
\text { Resilience Programme }\end{array}$ & 3 & 2 & 3 & 2 & 50 \\
\hline $\begin{array}{l}\text { 100. The intervention should also consider the importance of } \\
\text { gender differences and beliefs of the community }\end{array}$ & 7 & 1 & 1 & & 80 \\
\hline $\begin{array}{l}\text { 101. I was able to offer insight from my own research and } \\
\text { experience towards this process }\end{array}$ & 5 & 3 & & & 80 \\
\hline $\begin{array}{l}\text { 102. The community stakeholders should be involved to } \\
\text { action outcomes }\end{array}$ & 6 & 3 & 1 & & 90 \\
\hline $\begin{array}{l}\text { 103. Understanding the validity criteria of the instrument } \\
\text { used in the study was important for me }\end{array}$ & 4 & 2 & 2 & 1 & 60 \\
\hline
\end{tabular}

TAB LE 10 Thematic categories of round 3

The Family Resilience Strengthening Programme (FRSP)

1) FRSP content:

- About family

- Talking together

- Working together

- Closer together

2) FRSP structure and format

- Home visits

- Manualized

- Psychoeducative

- Action-based

The second module was termed talking together and will focus on establishing open and positive communication between family members. Liermann and Norton (2016) found that parents who were able to develop a way of communication with their children vastly improved the quality of their relationships. Improving communication patterns would also include educating family members of the different aspects of communication, for example, verbal and nonverbal, the latent and content messages of communication and activities to help demonstrate these aspects. Participants of the Delphi agreed that family members would need to develop a vocabulary of feeling words. Jonker and Greeff (2009) note that it is not only the act of talking together but also the style of communication that was integral to positive adjustment during crises. For example, the use of a positive and supportive style of communication is preferable to a negative and inflammatory communication style (Jonker \& Greeff, 2009). Improving family communication also serves an additional function: improving problem-solving skills (Walsh, 2016b). This is also in accordance with 
TAB LE 11 Family resilience strengthening programme

\begin{tabular}{|c|c|c|c|}
\hline Module & Aim & Outcomes & Possible activities \\
\hline About family & $\begin{array}{l}\text { To reflect on and make an } \\
\text { investment in their family }\end{array}$ & $\begin{array}{l}\text { Identify and draw from family } \\
\text { strengths } \\
\text { Develop a list of goals for } \\
\text { families }\end{array}$ & $\begin{array}{l}\text { Home-based visit } \\
\text { Map past successes and } \\
\text { existing strengths } \\
\text { Enter into agreement with } \\
\text { facilitator \& family (invest) }\end{array}$ \\
\hline Closer together & $\begin{array}{l}\text { To increase positive feelings of } \\
\text { family cohesion and } \\
\text { connectedness }\end{array}$ & $\begin{array}{l}\text { Mutual knowledge of each } \\
\text { family member } \\
\text { Understanding roles, rules, } \\
\text { boundaries } \\
\text { Develop sensitivity to each } \\
\text { others' needs } \\
\text { Learn about the structured and } \\
\text { unstructured dimension }\end{array}$ & $\begin{array}{l}\text { Defining family members' roles } \\
\text { \& rules } \\
\text { Spending quality time together } \\
\text { Role plays } \\
\text { Participant approach: empathy, } \\
\text { humor, attention }\end{array}$ \\
\hline Talking together & $\begin{array}{l}\text { Increase positive and effective } \\
\text { family communication } \\
\text { between members }\end{array}$ & $\begin{array}{l}\text { Learn about the value of family } \\
\text { communication } \\
\text { Making-meaning of } \\
\text { communication } \\
\text { Become aware of verbal \& } \\
\text { nonverbal communication } \\
\text { Sharing personal experiences } \\
\text { Listening vs. hearing }\end{array}$ & $\begin{array}{l}\text { Learn the act of talking } \\
\text { together } \\
\text { Role-plays } \\
\text { Taping a family discussion of an } \\
\text { agreed-upon family challenge } \\
\text { Develop feeling-words } \\
\text { vocabulary }\end{array}$ \\
\hline Working together & $\begin{array}{l}\text { Increase access to social } \\
\text { resources } \\
\text { Increase access to economic } \\
\text { resources }\end{array}$ & $\begin{array}{l}\text { Explore available resources } \\
\text { Learn about resources \& rights } \\
\text { to resources } \\
\text { Learn about financial } \\
\text { management }\end{array}$ & $\begin{array}{l}\text { Develop pamphlets, service } \\
\text { details, contact info } \\
\text { Learn budgeting } \\
\text { How to engage local and } \\
\text { broader government }\end{array}$ \\
\hline
\end{tabular}

Walsh's theory, in that the role of family communication (as a key resilience construct) is most useful in solving family problems. The range of socioeconomic family problems experienced, however, might supersede what families are able to accomplish by simply "being resilient" (Walsh, 2016a).

We focus on increasing the knowledge and use of social and economic resources of the third module, named working together. The importance of social and economic resources in family functioning has been established consistently in different conceptual and empirical studies (for example, Benzies \& Mysachiuk, 2009; Distelberg \& Taylor, 2015; Power et al., 2016). Yet the socioeconomic inequality of these multichallenged families is a concern. In the first phase of the larger project, many participants referred to the severe lack of socioeconomic resources and opportunities in the community. The socioeconomic inequality in South Africa is one of the highest in the world (Maiorano \& Manor, 2017).

Findings from this study suggests that the aim of this module should be to help family members map out or learn about existing social and economic resources, as well as creating opportunities to enhance resources within their community. In other words, participants would gain knowledge of the local services offered within the community and larger society. One of the most important contributors to healthy family functioning necessitates a statewide commitment in all aspects of family life (Walsh, 2016a).

Participants in the program will also learn how to be more explicit of their families' needs and discover ways in which those needs can be met. For example, many families in the community rely on a social grant from the Department of Social Development. Receiving financial assistance alone does not equate to knowledge of financial planning. Learning the importance of financial management and curriculum vitae development are examples of two activities in which participants can acquire skills and gain some financial empowerment and responsibility.

Another recommendation from participants was to ensure that there is adequate engagement with local government and broader institutions to create better opportunities within the communities. The LINC community resilience model has proven that establishing links (either an individual or an organization who performs a liaison function) among professionals, leaders, other decision makers, and the community results in a collaborative relationship and improves individual, family, and community outcomes (Landau, 2010). This will be a good guideline within this module. 
Decisions were also made in terms of the program structure and format. First, the program will be psychoeducative. This was in accordance with the findings of many intervention studies that have utilized this approach (Lim \& Han, 2013; Riley et al., 2008; Saltzman, 2016). Second, the program would also be action-based. In other words, participants of the program will have several opportunities to practice what they will learn during the course of the program through various activities. Third, the community stakeholders believed strongly that some sessions should be home-based. They referred to interventions that they conducted previously in which home-based sessions proved useful. This has also been found in Riley et al. (2008) as a useful method for engaging participants and increasing retention in a program and the likelihood of the success of the program. Last, manuals and worksheets will be developed to assist facilitators and participants of the program. Participants will have tangible materials to use during and after the program and will increase the fidelity and accessibility of the program (Holtzkamp, 2010; Riley et al., 2008).

Further, the synergistic effect of family resilience processes has been demonstrated in several studies (Jonker $\&$ Greeff, 2009; Offer, 2013; Saltzman, 2016) as well as the current study. For example, in the questionnaire, one of the factors suggested under the theme of family communication was "family times for planning activities"-a factor that is also associated with family connectedness. Similarly, Saltzman, Lester, Milburn, Woodward, and Stein (2016) posits that enhancing family resilience processes can reduce additional challenges experienced by individual family members, thereby increasing change within the entire family system.

To maintain the contextual diversity and participatory action model used in the development of the program, the FRSP will continue with a "guideline" approach and not be too prescriptive in activities; goals should be directed by the family themselves (Walsh, 2016).

\subsection{Limitations and recommendations}

The sample size within this study was smaller than anticipated. We had hoped to reach closer to 15 participants because Macmillan, King, and Tully (2016) have suggested this as the average; however, this was not possible. Another method to consider in the future would be to include the community stakeholder groups with the Delphi rounds and conduct an interrater reliability analysis. This could illuminate differences or similarities between academics and researchers as well as grassroots community workers.

According to Hsu and Sandford (2007), precaution should also be practiced when considering "expert" responses because not all participants will be equivalent in their knowledge. However, this study is the final stage of a three-phase project. Information has been gathered from empirical research studies, both published and grey literature, as well as information collated through a series of data collected from community members and meetings with stakeholders. Therefore, we feel that the present study is an accurate, congruent reflection of the work in family studies and what is possible through international and local collaboration. The next step of the process is to begin writing the manuals for the facilitators and program participants while being mindful of appropriate evaluation strategies. This will increase the success of evaluating and monitoring a pilot.

\section{$4.2 \mid$ Conclusion}

The aim of this study was to describe the development of a community-based family resilience program in a rural community along the West Coast of South Africa. A three-round Delphi was utilized with two distinct cohorts: The first was a panel of 10 experts practising and conducting research in the field of child and family studies, and the secondwas a group of community stakeholders working in the local NGO, who were able to provide input with reference to the contextual realities of the community. This study highlights the importance of contextual and evidence-based work in applied research. It also emphasizes that family theorists, clinicians, and researchers should advocate for transformation, especially in bridging structural inequality gap in South Africa.

The family resilience dimensions are evident across disciplines from social work, trauma, developmental, community psychology, nursing to the military. These dimensions are also present across cultures. However, as was the case in Stuart and Jose (2014) and Manzi et al. (2006), the extent to which a factor, such as family differentiation, is evident in 
one culture compared to another varies. Based on the literature review herein, not many programs have used a family resilience theory as its developmental frame. Yet these studies have also shown the positive effects of family resilience processes such as communication and problem solving, family cohesion, and social support. This study has also shown the interwoven or synergistic nature of individual, family and community systems.

A family's sense of security and harmony is unquestionably important and although a family resilience intervention might improve certain aspects of family life, this does not always minimize the effects of adversity (Black \& Lobo, 2008). Moreover, it especially does not preclude the rights that all individuals have to be protected from structural adversity. If a society does not provide for its people adequately, optimally, and greatly, it cannot possibly hope for people to provide for themselves. We hope this study demonstrated not only the importance of family and its challenges but also the variety of family needs, which need to be met by individuals and parties in many sectors of society.

\section{ORCID}

Serena Ann Isaacs (iD http://orcid.org/0000-0002-5952-8614

\section{REFERENCES}

Acuña, M. A., \& Kataoba, A. (2017). Family communication styles and resilience among adolescents. Social Work, 62(3)261-269. https://doi.org/10.1093/sw/swx017

Adams, S., Carels, C., Savahl, S., Isaacs, S., Brown, Q., Malinga, M., ... Zozulya, M. (2013). Alcohol abuse and risky sexual behaviour among young adults in a low socio-economic status community in Cape Town. Journal of Substance Use, https://doi.org/10.3109/14659891.2012.754059

Baer, J. (2002). Is family cohesion a risk or protective factor during adolescent development? Journal of Marriage and Family, 64(3), 668-675.

Benzies, K., \& Mychasiuk, R. (2009). Fostering family resiliency: A review of the key protective factors. Child and Family Social Work, 14, 103-114.

Black, K., \& Lobo, M. (2008). A conceptual review of family resilience factors. Journal of Family Nursing, 14(33)

Braun, V., \& Clarke, V. (2006). Using thematic analysis in psychology. Qualitative Research in Psychology, 3(2), 77-101.

Caffarella, R. S. (2002). Planning programs for adult learners: A practical guide for educators, trainers, and staff developers (2nd ed.). San Francisco: Jossey-Bass.

Crime Stats. (2013). Western Cape safety report 2012/2013. Retrieved from https://www.crimestatssa.com/provinceselect. php?ShowProvince=Western+Cape

Distelberg, B., \& Taylor, S. (2015). The roles of social support and family resilience in accessing healthcare and employment resources among families living in traditional public housing communities. Child and Family Social Work, 20, 494-506 https://doi.org/10.1111/cfs.12098.

Hasson, F., \& Kenney, S. (2011). Enhancing rigour in the Delphi technique research. Technological Forecasting and Social Change, 78, 1695-1704.

High, A. C., \& Scharp, K. M. (2015). Examining family communication patterns and seeking social support direct and indirect effects through ability and motivation. Human Communication Research, 41, 459-479. https://doi.org/10.1111/hcre.12061

Ho, H. C. Y., Mui, M., Wan, A., Ng, Y. L., Stewart, S. M., Yew, C., ... Chan, S. S. (2016). Happy Family Kitchen II: A cluster randomized controlled trial of a community-based family intervention for enhancing family communication and well-being in Hong Kong. Frontiers in Psychology, 7, 638-649. https://doi.org/10.3389/fpsyg.2016.00638

Hohmann, A. A., \& Shear, M. K. (2002). Community-based intervention research: Coping with the "noise" of real life in study design. American Journal of Psychiatry, 159, 201-207.

Holborn, L., \& Eddy, G. (2011). First steps to healing the South African family. Johannesburg: South Africa Institute of Race Relations. Retrieved from https://www.sairr.org.za/services/publications/occasional-reports/files/first-steps-to-healing-thesouth-african-family-final-report-mar-2011.pdf

Holey, E. A., Feeley, J. L., Dixon, J., \& Whittaker, V. J. (2007). An exploration of the use of simple statistics to measure consensus and stability in Delphi studies. BMC: Medical Research Methodology, 7, 52. https://doi.org/10.1186/1471-2288-7-52

Holtzkamp, J. (2012). The development and assessment of a family resilience enhancement programme. Unpublished doctoral thesis. Stellenbosch: University of Stellenbosch. 
Hsu, C., \& Sandford, B. A. (2007). The Delphi technique: Making sense of consensus. Practical Assessment, Research and Evaluation, 12(10), 1-8.

Hubler, D. S., Burr, B. K., Gardner, B. C., Larzelere, R. E., \& Busby, D. M. (2015). The intergenerational transmission of financial stress and relationship outcomes. Marriage and Family Review. https://doi.org/10.1080/01494929.2015.1100695

Isaacs, S., Roman, N. V., \& Savahl, S. (in press). An exploration of the family resilience needs of a rural community in South Africa: A sequential explanatory mixed methodological study design. Current Psychology.

Isaacs, S., Roman, N. V., Savahl, S., \& Sui, X. C. (2017). Using the RE-AIM framework to identify best practice models for family intervention development: A systematic review. Child and Family Social Work. https://doi.org/10.1111/cfs.12380

Jonker, L., \& Greeff, A. P. (2009). Resilience factors in families living with people with mental illnesses. Journal of Community Psychology, 37(7), 859-873. https://doi.org/10.1002/jcop.20337

Landau, J. (2010). Communities that care for families: The LINC model for enhancing individual, family, and community resilience. American Journal of Orthopsychiatry, 80(4), 516-524. https://doi.org/10.1111/j.1939-0025.2010.01054.x

Landau, J., \& Weaver, A. M. (2006). The LINC model of family and community resilience: New approaches to disaster response. Journal of Family and Consumer Studies, 98(2), 11-14.

Law, P. C., Cuskelly, M., \& Carroll, A. (2013). Young people's perceptions of family, peer and school connectedness and their impact on adjustment. Australian Journal of Guidance and Counselling, 23(1), 115-140. https://doi.org/10.1017/jgc.2012.19

Lester, P., Stein, J. A., Saltzman, W., Woodward, K., MacDermid, S. W., Mitburn, N., ... Beardslee, W. (2013). Psychological health of military children: Longitudinal evaluation of a family-centered prevention program to enhance family resilience. Military Medicine, 178(8), 838.

Liermann, K., \& Norton, C. L. (2016). Enhancing family communication: Examining the impact of a therapeutic wilderness program for struggling teens and parents. Contemporary Family Therapy, 38, 14-22. https://doi.org/ 10.1007/s10591-015-9371-5

Lim, H. S., \& Han, K. S. (2013). Effects of the Family Resilience Enhancement Program for families of patients with chronic schizophrenia. Journal of Korean Academy of Nursing, 43(1), 133-142. https://doi.org/10.4040/jkan.2013.43.1.133

Manzi, C., Vignoles, V. L., Regalia, C., \& Scabini, E. (2006). Cohesion and enmeshment revisited: Differentiation, identity, and well-being in two European cultures. Journal of Marriage and Family, 68, 673-689.

McMillan, S. S., King, M., \& Tully, M. P. (2016). How to use the nominal group and Delphi techniques. International Journal of Clinical Pharmacy, 38, 655-662. https://doi.org/10.1007/s11096-016-0257-x

Offer, S. (2013). Assessing the relationship between family mealtime communication and adolescent emotional well-being using the experience sampling method. Journal of Adolescence, 36, 577-585. https://doi.org/ 10.1016/j.adolescence.2013.03.007

Okoli, C., \& Pawlowski, S. D. (2004). The Delphi method as a research tool: An example, design considerations and applications. Information \& Management, 42(1), 15-29.

Pathways to Resilience IV: Global South Perspectives. (14-16 July 2017). Amarasingam, A., Thomas de Benitez, S., Benjamin, L., Lazarus, S. Is resilience futile? Adaptation in contexts of structural and social disadvantage. Cape Town, South Africa.

Patterson, J. (2002). Integrating family resilience and family stress theory. Journal of Marriage and Family, 64(2), $349-373$.

Power, J., Goodyear, M., Maybery, D., Reupert, A., O'Hanlon, B., Cuff, R., \& Perlesz, A. (2016). Family resilience in families where a parent has a mental illness. Journal of Social Work, 16(1), 66-82. https://doi.org/10.11771146817314568081

Prouty, A. M., Fischer, J., Purdom, A., Cobos, E., \& Helmeke, K. B. (2016). Spiritual coping: A gateway to enhancing family communication during cancer treatment. Journal of Religion and Health, 55, 269-287. https://doi.org/10.1007/s10943-015-0108-4

Riley, A. W., Valdez, C. R., Barrueoco, S., Mills, C., Beardslee, W., Sandler, R., \& Rawal, P. (2008). Development of a family-based program to reduce risk and promote resilience among families affected by maternal depression: Theoretical basis and program description. Clinical Child and Family Psychology Review, 11, 12-29. https://doi.org/10.1007/s10567-008-0030-3

Rowe, G., \& Wright, G. (2011). The Delphi technique: Past, present, and future prospects-Introduction to the special issue. Technological Forecasting and Social Change, 78, 1487-1490. https://doi.org/10.1016/j.techfore.2011.09.002

Saltzman, W. R. (2016). The FOCUS Family Resilience Program: An innovative family intervention for trauma and loss. Family Process, 55(4), 647-659. https://doi.org/10.1111/famp.12250

Saltzman, W. R., Lester, P., Beardslee, W. R., Layne, C. M., Woodward, K., \& Nash, W. P. (2011). Mechanisms of risk and resilience in military families: Theoretical and empirical basis of a family-focused resilience enhancement program. Clinical Child and Family Psychology Review, 14, 213-230 https://doi.org/10.1007/s10567-011-0096-1

Saltzman, W. R., Lester, P., Milburn, N., Woodward, K., \& Stein, J. (2016). Pathways of risk and resilience: Impact of a family resilience program on active-duty military parents. Family Process, 55, 633-646. 
Schrodt, P., Ledbetter, A. M., Jernberg, K. A., Larson, L., Brown, N., \& Glonek, K. (2009). Family communication patterns as mediators of communication competence in the parent-child relationship. Journal of Social and Personal Relationships, 26(6-7), 853-874.

Seccombe, K. (2002). Beating the odds versus changing the odds: Poverty, resilience and family policy. Journal of Marriage and Family, 64, 384-394.

Skulmoski, G. J., Hartman, F. T., \& Krahn, J. (2007). The Delphi method for graduate research. Journal of Information Technology Education, 6, 1-21.

Soliz, J., Thorson, A. R., \& Rittenour, C. E. (2009). Communicative correlates of satisfaction, family identity, and group salience in multiracial/ethnic families. Journal of Marriage and Family, 71, 819-832.

Stiel, L., Estrella, J., Wang, S., \& Distelberg, B. (2014). Family resilience predicts socioeconomic mobility of HUD participants. Journal of Human Behavior in the Social Environment, 24, 759-774. https://doi.org/10.1080/10911359.2013.873755

Stuart, J., \& Jose, P. E. (2014). The protective influence of family connectedness, ethnic identity, and ethnic engagement for New Zealand Maōri adolescents. Developmental Psychology, 50(6), 1817-1826.

van Oostrom, S. H., Anema, J. R., Terluin, B., Venema, A., de Vet, C. W., \& van Mechelen, W. (2007). Development of a workplace intervention for sick-listed employees with stress-related mental disorders: Intervention Mapping as a useful tool. BMC Health Services Research, 7, 127 https://doi.org/10.1186/1472-6963-7-127

Vermeulen, T., \& Greeff, A. P. (2015). Family resilience resources in coping with child sexual abuse in South Africa. Journal of Child Sexual Abuse, 24, 555-571. https://doi.org/10.1080/10538712.2015.1042183

von der Gracht, H. A. (2012). Consensus measurement in Delphi studies: Review and implications for future quality assurance. Technological Forecasting \& Social Change, 79, 1525-1536. https://doi.org/10.1016/j.techfore.2012.04.013

Walsh, F. (2003). Family resilience: A framework for clinical practice. Family Process, 42(1), 1-18.

Walsh, F. (2006). Strengthening family resilience(2nd ed.). New York: The Guilford Press.

Walsh, F. (2012). Family resilience: Strengths forged through adversity. In F. Walsh (Ed.), Normal family processes( 4th ed., pp. 399-427). New York: Guilford Press.

Walsh, F. (2016a). Strengthening family resilience (3rd ed.). New York: The Guilford Press.

Walsh, F. (2016b). Applying a family resilience framework in training, practice, and research: Mastering the art of the possible. Family Process, 55, 616-632.

\section{SUPPORTING INFORMATION}

Additional Supporting Information may be found online in the supporting information tab for this article.

How to cite this article: Isaacs Serena Ann, Roman Nicolette V., Savahl Shazly. The development of a family resilience-strengthening programme for families in a South African rural community. J Community Psychol. 2018;46:616-635. https://doi.org/10.1002/jcop.21962 